\title{
COVID-19 pandemic and pharmacy education in a developing country: A case study from Nigeria
}

\author{
B.K. Lawal*, A. Haruna, F.S. Kurfi, K.B. David \\ Faculty of Pharmaceutical Sciences, Kaduna State University, Nigeria
}

\author{
Keywords \\ Teaching \\ Kaduna State \\ E-learning \\ Pharmacy Education \\ Nigeria \\ ${ }^{*}$ Corresponding author: \\ lawalbasira@yahoo.com \\ basira.lawal@kasu.edu.ng
}

\begin{abstract}
Summary: Since March 2020, all schools in Nigeria have been closed to curtail the spread of the COVID-19 virus. This paper presents the case study of the e-learning strategies adopted by Kaduna State University to reduce the educational disruption during these unprecedented times. As the University had no established e-learning resources, there was a need for prompt training of staff in online teaching. The online teaching methods to be adopted came with their fair share of challenges as e-learning activities had not been taking place at the University prior to the emergence of COVID-19. The University, with the full support of the state government, were making plans to ensure a fixed structure for the integration of e-learning into the syllabus. This case study provides some recommendations that could be adopted by similar institutions that have no previous e-learning structures. The COVID-19 pandemic has opened up opportunities to upgrade the educational mode of delivery and shown the need to embrace emerging technologies.
\end{abstract}

\section{Background and Context}

Globally, the coronavirus (COVID-19) pandemic continually poses a challenge to all aspects of education. It has greatly disrupted the global educational sector since several countries took unprecedented measures to control the spread of the virus by initiating partial or complete lockdowns. On the 19th March 2020, the Nigerian government decided to close all tertiary, secondary and primary schools in the country (Olaleye, 2020).

In Africa, pharmacy education continually faces numerous challenges that require interventions to maximise the students learning experiences (Okoro \& Biambo, 2020). Considering these challenges, pharmacy students may not only be overwhelmed and anxious about life after school, but also be concerned about their studies, assessments, school timetable, graduation, competencies and the impact of the pandemic on their career trajectories (Adebisi, Agboola, \& Okereke, 2020).
Due to the uncertainty as to when schools might be reopened, the need to prepare pharmacy students for other modes of teaching and learning cannot be overemphasised. Schools across the globe have thus been forced to explore and move to e-learning platforms. In Nigeria, many universities lack adequate infrastructure or resources to facilitate online teaching, with only a few universities (mostly privately owned) using e-learning platforms before the pandemic (Ogaji, \& Ojabo, 2014).

This case study describes the approach taken by the Kaduna State University to support and encourage student learning during these unprecedented times.

\section{Educational Description}

In Nigeria, the adoption of information and communication technology (ICT) in pharmacy schools is limited. Pharmacy education in Nigeria is mostly through a didactic approach. 
Infrastructural challenges, lack of proper training of academic staff in ICT and lack of access to quality teaching resources are among the challenges which impact the quality of delivery of pharmacy education in Nigeria (Adebisi, Agboola, \& Okereke, 2020). Kaduna State University, a state government owned university, realised they needed to learn from the critical situation the institution was facing. The university organised and planned for the adoption of e-learning methods immediately after schools were closed. Through the ICT department of the school, all academic staff were quickly trained on the use of e-learning platforms, specifically Google Meet. The training was meant to introduce lecturers to virtual teaching as most staff were lacking online teaching experience. This was expected to serve as a basis for improving infrastructure and eventually making online teaching and learning an integral part of teaching and learning at the institution.

Immediately after the training, new lecture timetables were prepared to cater for the online teaching. Considerations were made to allocate a maximum of $\mathbf{4 0}$ minutes per class, dividing teaching content into smaller units, and classes arranged in such a way to make it easy for students that may have to move to areas with a better internet connection to attend their online classes. All practical classes were removed from the timetable, with faculty still considering how best to approach the practical classes as most of the practicals require a hands-on approach and as such will require massively disruptive shifts and preparations.

E-lectures commenced but along the way, many challenges were encountered that have hindered the smooth uptake of the virtual classes. It was observed that many students (sometimes half the class) were unable to attend the online classes due to multiple factors. Most students, and even some lecturers, were complaining of data costs and lack of good internet connectivity. This has resulted in the use of alternative modes of teaching that are not gravely affected by the strength of internet connectivity and do not consume much data, such as the use of a WhatsApp group to transfer interactive lecture notes to students. Also, links to relevant YouTube videos were sometimes sent to students to maximise their learning capabilities. The use of interactive lecture notes cannot be overemphasised as it enabled the students to have a better understanding whilst being on selfstudy. Additionally, it is important to consider that students may lack the self-discipline to study, suitable learning materials, a good learning environment or computer facilities when they are in self-isolation during the pandemic. To support the students the University, in collaboration with the state government, is providing laptops on loan service to students who require them.

Other methods adopted by lecturers to facilitate learning include the use of voice over lectures on PowerPoint and video recordings.

\section{Outcomes and Recommendations}

Kaduna State University is one of the very few institutions in Nigeria that has continued teaching and learning during this pandemic. Although there has been many hurdles and challenges, students are still enthusiastic, likewise the teachers. The uptake of the online learning has resulted in the state government expanding the system into an institutional based e-learning platform. Consultants have already been engaged who have developed the platform and ongoing training for all teaching and technical staff. The University is thus making plans to integrate the e-learning methods with its didactic teaching method when schools eventually reopen.

There are some recommendations from this case study for other similar institutions, particularly in Nigeria and other developing nations. Firstly, considering the universities socioeconomic challenges, fully online teaching may be difficult for students. A combination of synchronous and asynchronous methods may be more feasible. Teachers may need to consider short online classes with additional discussions via social-media channels like WhatsApp to further discuss topics taught which may not have been covered during the online classes. Secondly, students should be provided with mental health support through both peer and specialised support channels, and financial support such as loans to purchase laptops to promote learning. Thirdly, institutions should preferably develop their institutional based e-learning platforms. This will make it easier in tracking the progress of online teaching and ensuring accountability.

This paper highlights the faculty's experiences and challenges faced, which are very common in other institutions in developing nations. The teaching method employed for pharmacy education in Nigeria is currently facing severe challenges in planning the next academic year. However, the COVID-19 pandemic has opened up opportunities for an upgrade in the educational mode of delivery and the need to embrace emerging technologies.

\section{References}

Adebisi, Y.A., Agboola, P., \& Okereke, M. (2020). COVID-19 Pandemic: Medical and Pharmacy Education in Nigeria. International Journal of Medical Students (in press). https://doi.org/10.5195/ijms.2020.559

Ogaji, J., \& Ojabo, C. E. (2014). Pharmacy education in Nigeria: The journey so far. Archives of Pharmacy Practice, 5(2), 47-60. https:// doi.org/10.4103/2045-080X.132644

Okoro, O.N., \& Biambo, A.A. (2020.) Pharmacy students' perceived professionalism and application of bioethical principles: Implications for teaching pharmacy ethics for patient-centred pharmacy practice. Pharmacy Education, 20(1), 158 - 167. https://doi.org/10.46542/pe. $\underline{2020.201 .158167}$

Olaleye, A. (2020). Coronavirus: FG orders closure of varsities, schools nationwide (online). Available at: https://punchng.com/breakingcoronavirus-fg-orders-closure-of-varsities-schools-nationwide 